Article

\title{
An Ethnographic Look into Farmer Discussion Groups through the Lens of Social Learning Theory
}

\author{
Elizabeth Dooley \\ Centre for Rural Policy Research, University of Exeter, Exeter EX4 4PJ, UK; ed419@exeter.ac.uk
}

Received: 28 August 2020; Accepted: 14 September 2020; Published: 22 September 2020

check for updates

\begin{abstract}
Farmer discussion groups (FDGs) are a collaborative mechanism through which farmers can engage and learn from and with their peers. Participants cite numerous benefits from FDGs, e.g., economic, social, etc., but how learning happens in these contexts from an adult cognitive learning theory perspective is not well understood. Thus, Bandura's social learning theory was used to study seven FDGs in the South West of England. The objective was to determine whether social learning was occurring through the FDGs' interactions, examined according to three elements: (1) behaviour modelling, (2) role modelling and (3) self-reflexivity. An ethnographic methodology was utilised to gather rich empirical data through participant observation of 42 meetings and 24 semi-structured interviews. The results from 12 months attending FDG meetings demonstrated that behaviour modelling and role modelling were present in all FDGs. Self-reflexivity, however, was not evidenced as being promoted by all groups' interactions, which (facilitated) critical discourse amongst the FDG participants was found to foster. Thus, evidence of social learning was not found to be occurring as a result of all the FDGs' interactions. Collaborative learning processes that aim to promote social learning should build participants' capacity and skills, structure engagement and train facilitators to foster critical discourse that may help promote self-reflexivity from behaviour modelling and role modelling.
\end{abstract}

Keywords: farmer discussion group; social learning; collaborative; peer-to-peer; Bandura; self-reflexivity; critical discourse; facilitation

\section{Introduction}

Change is an omnipresent topic within UK agriculture at the moment, partly due to questions around how the agricultural policy framework will change upon the UK's exit from the EU Common Agricultural Policy, but also in light of ongoing technological innovations, shifting consumer preferences, farm business transitions, alternative contracts and entities, climate change, etc. In thinking about the changing nature of UK agriculture and the various impacts this might have on the farming population [1,2], farmer learning and knowledge exchange around innovative adaptations and transformative solutions offer a way in which producers can reduce negative impacts from change and increase their resilience [3-5]. The move away from the traditional "linear" model of knowledge transfer employed in extension and education toward knowledge exchange and farmer-led rather than researcher-driven processes provides the enabling environment to facilitate such innovative learning and change on family farms [6,7]. Farmers are viewed as proactive learners rather than passive recipients within Agricultural Innovation Systems (AIS) [6,8,9]. Collaborative learning processes aim to engage farmers in two-way knowledge exchange and build capacity as opposed to 'train' farmers [10-12].

Peer-to-peer (P2P) learning has been shown to be a particularly effective method for enhancing farmer learning [13-16]. Within the UK agricultural extension and education landscape, there are different collaborative mechanisms through which farmers can engage and learn from and with 
their peers, e.g., monitor farms, participatory workshops and seminars, multi-stakeholder networks, demonstration farms, open days, etc. [17]. Farmer discussion groups (FDGs) are another collaborative mechanism farmers may choose to engage with to varying extents depending on their comfort level with P2P learning processes. In previous studies, FDGs have been found to promote social interaction, collaboration, information exchange, and feedback based upon shared and observed ideas, approaches, problems and strategies; in terms of outcomes, participants also report enhanced managerial skills and in many cases improved profitability [18-20].

As Ingram et al. [21] found with regard to farmer learning enabled by demonstration farms, however, we do not have a well-developed understanding of how learning happens within the context of FDGs from the perspective of adult cognitive learning theory. The available empirical evidence speaks to the fact that farmers see FDGs as valuable with regard to learning, they will dedicate time and money to participating in organised meetings and discussions, and they may attribute changes made on-farm to what they have seen, heard and learned in FDGs [22-24]. How and why participation may lead to changes in knowledge, behaviour, values, intentions and engagement, however, requires us to take a step back and look at how it is that participants in FDGs acquire, process and utilise information and experiences from their peers. If we can better understand this process, FDGs (and P2P learning interactions more generally) may be more effectively designed and implemented to specifically promote that acquisition, processing and utilisation and lead to desired outcomes.

There are multiple theories of learning that draw from different areas of knowledge and understanding as to how people learn, e.g., social science, psychology, biology [25]. They diverge often due to their focus on the individual learner's internal cognitive processes or, alternatively, the external learning environment and the learner's interaction with it. Experiential learning, or "the transformation of experience into knowledge", is a widely used theory to explain the cognitive process whereby a learner experiences something, reflects upon what $\mathrm{s} /$ he observed, draws concepts from it and then experiments with implementing those concepts [26] (p. 47). Transformative learning is another prominent theory in the adult learning context, explaining the internal process whereby a "disorienting dilemma" challenges one to critically examine the assumptions (taken-for-granted values, projections, stereotypes, etc.) "supporting our own beliefs and expectations, as well as those of others" [27] (p. 23); [28]. This form of learning is profound and extensive, fundamentally shifting the learner's frames of reference or meaning making to be "more inclusive and accommodating of a wider range of experiences" [29] (p. 86). A theory focused on the external context's influence is situated learning within communities of practice, whereby engaging in social participation is a process of learning and knowing the shared meanings, practices, and resources for carrying out that community's joint enterprise [30]. Transitional learning theory focuses on the impact that societal transformations have on the learning process, which in line with biographical lifelong learning "triggers a continuous process of constructing meaning, making choices, taking up responsibilities and dealing with the changes in the personal and societal context" [31] (p. 232).

A critique of cognitive learning theories is their lack of emphasis on the nature of the learner's social interactions within their environment as affecting learning [25]. Whilst encountering diverse perspectives may be the trigger for transformative learning to occur, for instance, the learner's internal process leading to fundamental changes in perspective is the focus [7,9]. On the other hand, theories that focus on how and why social context may affect the way individuals receive, utilise, reproduce, etc. information and knowledge are criticised for missing a piece of the puzzle as to how individual characteristics and cognitive processing affect learning [25]. Social learning theory, however, directly relates the learner's environment and social interactions to her/his cognitive development and behaviour change [32]. Along these lines, Rodela [33] (p. 15) states that social learning has been operationalised to signify "a change in internal-reflective processes" through participation, which may even induce transformative learning. Widely adopted and adapted as a theoretical frame in many areas of research, social learning has been applied to some extent in the agricultural extension field, generally denoting a process involving groups of people coming together and learning around a shared 
objective, e.g., sustainable resource management [21]. As FDGs foster group interaction with the aim of promoting P2P learning, social learning seems as though it must be occurring in those spaces. The elements of Bandura's cognitive learning theory, however, have not been rigorously applied to understand whether FDGs cohere with social learning in practice [32,34].

Therefore, this paper aims to explore whether social learning, as understood from an adult cognitive learning theory perspective, occurs through FDGs' interactions, and if so, how and why. The data on which the analysis is based were collected as part of a $\mathrm{PhD}$ project, comprised of a year-long ethnographic study of existing FDGs in South West England. The article will be set out as follows. First, the conceptual framework used to explore and analyse FDGs' learning processes will be outlined, breaking down the elements of Bandura's social learning theory. This will be followed by an overview of the methodology employed in this project. Next, an overview of the sample is imperative to contextualise and draw from the different FDGs studied. Finally, results and discussion of the data will present how social learning elements were demonstrated amongst the groups as well as crucial factors and conditions to promote in collaborative learning situations in order to effectively foster social learning outcomes.

\section{Conceptual Framework}

Social learning theory has been used in many different fields of academic research since its conception, such as information systems, organisational studies and media and communication studies [35]. One area in particular is natural resource management, where social learning through collaborative, participatory activities results in changes in thinking and management [36,37]. It has also been applied in connection with systems thinking [38], communities of practice [39], and conceptualised as multi-loop learning [40]. Leeuwis and Aarts [9] provide a table with communication strategies for supporting social learning processes within networks for innovation, but as Beers et al. [7] point to within sustainability transitions, conceptualisation has mainly focused on outcomes rather than the process of learning drawing on the educational sciences. As critiqued by Reed et al. [41], studies have endeavoured to demonstrate that social learning occurs or is likely to result from people coming together around a common issue and sharing diverse insights, as evidenced by change-in how people think, what they intend to change, or how practice differs. Despite often referencing Bandura in relation to social learning, however, the elements of his cognitive learning theory have not been meaningfully engaged with in an attempt to understand why from a cognitive learning perspective the process of coming together and learning in that format may lead to changes in thought, intention and practice.

Social learning originated as a cognitive psychology theory regarding how humans learn through modelling and observation, resulting in behaviour change [32]. Bandura eventually renamed it social cognitive theory, emphasising that social learning goes beyond environmental influences causing reactive behaviour [34]. Rather, it can be understood as simultaneous interaction between the individual, his/her environment and behaviour (labelled triadic reciprocality), stimulating significant cognitive processing and development [42]. The theory posits, "By observing others, people acquire knowledge, rules, skills, strategies, beliefs, and attitudes. Individuals also learn from models the usefulness and appropriateness of behaviors and the consequences of modeled behaviors, and they act in accordance with beliefs about their capabilities and the expected outcomes of their actions" [42] (p. 118). The learner therefore exercises the capacity to think critically, "reflecting on the possible consequences of certain behaviours and then deciding on the best action" [43] (p. 74). Reflection has been described as a cognitive process of active, deliberate thinking aimed at rational, logical problem-solving or reflection-in-action-understanding new perspectives and ideas and building knowledge through experimentation [44]. Self-reflexivity, on the other hand, encapsulates a self-aware process of scrutiny and critical engagement in which the learner continuously questions and challenges her own ideas, beliefs, intentions, assumptions, processes and practices [45]. Building on this evolving perspective of the reflexive learner, the three elements of social learning processes framing this study were: (1) behaviour modelling, (2) role modelling, and (3) self-reflexivity [34]. 
Behaviour modelling may result in enactive (performed) and/or vicarious (observation and listening) learning from demonstration and explanation. The factors influencing learning under this element are:

- Attention-meaningful perception of the modelled action;

- Retention-rehearsing, coding and relating to previous knowledge;

- Production-compared to one's mental representation;

- Motivation-reasons for devoting time and interest.

Role modelling brings in the important concept that who is modelling behaviours, and how, will impact the learner's cognitive processing of the information, skills, practices, etc. demonstrated or explained. Perceived (positive or negative) reinforcement of the model's actions is one of the factors affecting the learner's motivation to act to achieve certain outcome (learning) expectations under this element. The learner's self-efficacy (belief about one's own capabilities), values, needs, social norms, incentives, etc. are also factors relating to the receptivity to knowledge and information from role models.

Self-reflexivity relies on the agency of those undergoing social learning, not just in terms of choice regarding content but also the process through which learners incorporate, activate and/or transfer and sustain behaviours, cognitions and affects over time [46-48]. Meaningful adult social learning processes move beyond enhancing or resulting in primarily task-orientated learning, whether behavioural- or cognitive-based, whereby self-regulation of performance is sufficient. Rather, the process of learning from one's peers, promoting engagement with other ways of thinking, analysing and doing, may challenge not only how one does something but also the reasons why. Thus, Bandura's original social learning element self-regulation was amended to self-reflexivity, denoting critical questioning of one's own and others' ideas, beliefs, attitudes, assumptions, processes and practices in relation to what has been modelled [46]. By reorientating learners' cognitive processing, outcome expectations and self-efficacy towards awareness of and advancement in how they think about their thinking, continuously assessing their progress and needs along their learning journey, social learning processes may thereby also promote metacognitive development [27].

Thus, learning is a socially situated process, but simply because groups of people come together with the objective to learn, that does not automatically mean social learning is occurring. In endeavouring to understand whether social learning occurs through FDGs' interactions, therefore, this inquiry was framed by three key elements building on Bandura's original theory: behaviour modelling, role modelling and self-reflexivity.

\section{Methodology and Sample}

Taking this understanding of social learning theory forward, an ethnographic study of seven FDGs was conducted in South West England. The research project was designed in recognition of the lack of empirical observation and assessment of on-the-ground farmer learning, behaviour change in technical practice and decision making and innovation processes. Rose et al. [49] highlight that, to date, studies have often aimed to understand farmer behaviour or measure learning through intention to change. Ethnography is pointed to as an underused methodology, and longitudinal studies monitoring farmers' actual rather than "reported" behaviour change are lacking.

Ethnography is "a style of research that is distinguished by its objectives, which are to understand the social meanings and activities of people in a given 'field' or setting, and its approach, which involves close association with, and often participation in, this setting" [50], (p. 11) (emphasis in original). Thus, the aim in committing to at least a year of following a small number of groups was to dedicate the necessary amount of time and care to relationship building with the members of the groups in order to gain deep insights into their critical exchanges, history, relationships, power structures, meaning making, etc. [50]. 
Recruitment: Access was predominantly gained to the private groups through their facilitators/coordinators, who acted as Gatekeepers. There is no overarching directory of FDGs throughout the South West, let alone the country, so locating possible groups was the first step. Many FDGs are privately funded by the participants and therefore not advertised to the public. Organisations that run groups may be locatable, but often their FDGs are not open to the public, restricting attendance by farming sector, location, membership, fee, etc. Thus, a preliminary scoping exercise was carried out via online search as well as word-of-mouth inquiries to the local farm management association, levy body, veterinary companies, university research centre, etc. Six identified Gatekeepers from the surrounding area were then invited to a half-day workshop (only four could attend) at the University of Exeter, where the research project was introduced and the results from the scoping exercise were collaboratively expanded to include more existing groups in the South West of England. A sample of FDGs was selected from the compiled list and the facilitators/coordinators were individually approached to ask whether s/he would act on behalf of the researcher and ask their FDG members whether the researcher could attend an initial meeting. Immediately upon attending each group's initial meeting, the research project was explained, permission was requested and informed consent was gained to observe them for a year.

Participant observation: All group meetings possible for the selected FDGs were attended (42 in total) and detailed field notes recorded in a research journal. Inactive participant observation was the approach: watching, listening and recording insights about the group interactions [50]. Active participation was purposely refrained from to avoid potentially skewing the conversations between the participants. Depending on the context, handwritten notes were not possible or appropriate during some meetings. Instead, auditory notes were recorded on the drive back from the meeting. All notes were typed up to perform thematic analysis and stored on the University of Exeter server.

Semi-structured interviews: Five interviews were held with the groups' facilitators/coordinators during the first three months of fieldwork to discuss the approach towards fostering learning within each group. During months 5-11, 19 farmer interviews were conducted. By then, the researcher had attended multiple meetings and was familiar to the members. The original plan was to interview three members per group, but access to individual members was denied by two of the groups' sponsoring organisation (Beef/Sheep A and B, see Table 1). Thus, 3-4 farmers from Dairy A-D and the Veg Growers as well as two from additional groups were selected based on their participation observed within group meetings (e.g., bold, shy, knowledgeable), length of tenure farming and in the group (both recent entries and long-term operators), facilitator recommendation, and willingness to be interviewed. The interviews were approximately one hour in length and held in a location most convenient for the interviewees, usually around their kitchen tables. Interviews were recorded with informed consent and the recordings were anonymised and stored on the University of Exeter server. The aim in using this method was to supplement the participant observations by following up on interactions that evidenced the elements of the conceptual framework. In particular, they explored the participants' perception of how modelling contributed to their learning, role models within the group and whether/how self-reflexivity was promoted through their interactions with peers. Thematic analysis of the interviews was performed through (at least) double review with detailed timestamped notes, quoting and listening again for context, tone of voice, pauses, etc. [51]. 
Table 1. Farmer discussion groups followed for participant observation in South West England.

\begin{tabular}{ccccccc}
\hline Type & $\begin{array}{c}\text { Meeting } \\
\text { Frequency }\end{array}$ & Composition & Public/Private & Life Span & Format & Structure \\
\hline $\begin{array}{c}\text { Beef/Sheep } \\
\text { A }\end{array}$ & $\begin{array}{c}\text { Approx. 6× } \\
\text { per year }\end{array}$ & $\begin{array}{c}\text { Approx. 25 of } \\
500+\text { email list }\end{array}$ & Semi-Public & 6 years & $\begin{array}{c}\text { Expert } \\
\text { presentation/ } \\
\text { farm walk }\end{array}$ & $\begin{array}{c}\text { Organisation-led/ } \\
\text { Coordinator }\end{array}$ \\
\hline Beef/Sheep B & $\begin{array}{c}\text { Approx. } 3 \times \\
\text { per year }\end{array}$ & $\begin{array}{c}\text { Approx. 15 of } \\
500+\text { email list }\end{array}$ & Semi-Public & 6 years & $\begin{array}{c}\text { Expert } \\
\text { presentation/ } \\
\text { farm walk }\end{array}$ & $\begin{array}{c}\text { Organisation-led/ } \\
\text { Coordinator }\end{array}$ \\
\hline Dairy A & $7 \times$ per year & 15 farms & Private & 20+ years & $\begin{array}{c}\text { Farm walk/ } \\
\text { benchmark }\end{array}$ & Facilitator-led \\
\hline Dairy B & $11 \times$ per year & 15 farms & Private & 17 years & $\begin{array}{c}\text { Farm walk/ } \\
\text { benchmark }\end{array}$ & Facilitator-led \\
\hline Dairy C & $5 \times$ per year & $\begin{array}{c}10 \text { farms } \\
\text { Dairy D }\end{array}$ & Private & 13 years & $\begin{array}{c}\text { Farm walk/ } \\
\text { benchmark }\end{array}$ & Facilitator-led \\
\hline Veg Growers & $\begin{array}{c}\text { Approx. 15 } \\
\text { members, 100+ } \\
\text { email list }\end{array}$ & Semi-Public & 1 year & $\begin{array}{c}\text { Expert } \\
\text { presentation/ } \\
\text { farm walk }\end{array}$ & $\begin{array}{c}\text { Organisation-led/ } \\
\text { Facilitator }\end{array}$ \\
\hline
\end{tabular}

Sample: Participant observation was repeatedly conducted of seven groups, which maintained learning as one of their key objectives. Due to funding and travel limitations of the study, all were located in Devon, Cornwall, Somerset or Dorset. Despite the predominance of grazing livestock farms in the South West [52], there were more dairy FDGs identified in the scoping exercise than beef and sheep or arable and horticulture. Thus, four dairy groups were approached and agreed to participate, as well as two beef and sheep groups and one group composed of small-scale vegetable growers. Dairy D and Beef/Sheep A were women's groups and Beef/Sheep B was for young farmers, whilst Dairy A and C were predominantly male-attended. Dairy B had 3-4 women who regularly attended on behalf of the farm, and the Veg Growers was relatively evenly split in terms of gender. The private groups with stable, limited memberships were all funded by an annual fee of between $£ 250$ and $£ 350$ per farm, which covered the facilitators' time, meeting costs and annual trip. The semi-public groups were open to all members signed up to an email list, managed by an organisation to which a nominal fee of between $£ 5$ and $£ 10$ was paid per meeting, or independently amongst the farmers for no fee. Only a small number of the semi-public groups' possible participants attended each meeting, and the general public would not have been aware of or invited to any of the groups' meetings as they were not publicised beyond the members. Groups Dairy A-C benchmark against each other, meaning they complete and share full financial breakdowns with key performance indicators (KPIs). Dairy A and C were autumn-block calvers (meaning they sync their herd to calve ideally within a 6-week block in late August-October) and Dairy B were spring-block calvers (so their intense calving period occurs in February-March). Gaining access to all the groups' (semi-)privately-held meetings was very much an issue, so the sample was additionally influenced by the reliance on Gatekeepers' approval and assistance. Table 1 shows a breakdown of the FDGs followed.

For general context as to how the FDGs' meetings functioned, the expert presentation groups (Beef/Sheep A and B; Dairy D) convened in pub function rooms, cafés or farm offices for 2-3 h during the day or evening and listened to a presentation about a select topic (e.g., mental health). Questions were asked of the presenter and then lunch/supper/cake and tea were served and the participants had time to socialise. Alternatively, a farm walk led by the host was the focus of the meeting rather than an expert presentation. The benchmarking groups (Dairy A-C) all met during the day for $3-4 \mathrm{~h}$ on a fellow member's farm or an external farm that highlighted a particular learning point (e.g., labour, efficiency, size, grass utilisation). Members either brought a packed lunch or went to a pub for lunch after the farm walk led by the host and discussion facilitated by the facilitator. The Veg Growers 
met on each other's farms in the evening for 3+ hours and everyone brought a dish to share for a potluck following the farm walk led by the host and/or discussion led by either the host or farmer coordinators. Groups Beef/Sheep A and B and Dairy A-D suggested ideas for meeting topics, which the facilitators/coordinators tried to accommodate with an appropriate host/expert and agenda. The Veg Growers democratically decided on a season of topics and asked for volunteers within the membership to host for each meeting theme. None of the FDGs were implementing set programmes with externally imposed objectives; learning, collaboration, support, improved profitability and efficiency were some of the internal objectives of the groups.

\section{Results}

Whilst the FDGs shared many similarities, they also varied in context, group dynamics, history, etc. As emphasised in previous studies regarding FDGs [53], a limited size of between 15 and 20 participants seemed to function best in reducing the risk of fragmented side discussions, though this often happened for limited segments, e.g., when the group paused to examine the milking parlour, silage pit, propagation hoop house, etc. Maintaining a unified core discussion during farm walks often depended on both the presentation style of the host (e.g., engaging, asking for constructive criticism, debating how to do things differently) and active monitoring and reconvening by the facilitator/coordinator. The latter reiterates another structural component previously found to be crucial in promoting effective learning in FDGs, facilitation by a well-qualified and trusted facilitator who can foster farmer-led discussion on farmer-initiated topics [54]. Four groups (Dairy A-D) had professional facilitators leading each meeting, who acted not only as timekeepers and agenda leaders to keep things on track, but they also intervened with questions or examples to stimulate the discussion, presented KPIs if members submitted some before each meeting and employed analytical tools (e.g., SWOT analysis (strengths, weaknesses, opportunities and threats)) in instances where the host farmer asked for group input into a major decision, such as succession planning or investing in a new building. The coordinator for Beef/Sheep A and B acted more as a timekeeper and agenda leader but would interject questions if the participants were struggling to formulate them or a fresh line of inquiry was needed. The Veg Growers, being in the early stages of their group, were still undergoing discussions about who should "lead" as some were hesitant to host because they were nervous to be the focal point and present on the farm walk. The farmers co-coordinating the email list and organising the hosts for each topic, however, were hesitant from a democratic standpoint to always lead the discussion.

Farmers overwhelmingly spoke very positively about the FDGs "getting us off the farm" and collaborating, even though they required investment of both time and money. Sometimes their participation had spanned several decades, which suggested they saw continued membership and attendance as "worth it". When asked why, they spoke about the social element and the chance to "have a nosy" on other people's farms and see how they do things; but invariably, a key driver of their engagement was learning.

The following results provide a sample of the data collected from the participant observation and semi-structured interviews regarding the three elements of social learning theory explored. As an ethnographic approach was utilised, the examples were selectively chosen based on the richness of the event in demonstrating the elements and thick descriptions of the context have been provided as much as possible [50].

\subsection{Behaviour Modelling}

Almost every FDG meeting attended involved knowledge sharing and learning opportunities between participants through behaviour modelling. If the format included a host farm presentation and/or a farm walk, behaviour modelling was inherently a key component of the tour. The host farmer would show and/or explain how s/he does certain practices (e.g., intercropping, irrigation, beef finishing), thinks about processes (e.g., self-feeding from silage clamps, scraping yards, water trough placement in subdivided fields), or manages staff in carrying out tasks, decisions, etc. (e.g., 
recruitment and training, tracking colostrum administration, monitoring calf signs for pneumonia). Observation of these modelled behaviours may accelerate learning if the participants meaningfully perceive them (attention) and code or relate the information to their previous knowledge and experience (retention). Thus, participants can absorb novel information without directly doing or practising it (vicarious learning) [42]. This was often the only way in which learning happened during the short meetings rather than enactive learning (learning by doing) or production where the mental representation of the information was put into practice, although tactile engagement was witnessed multiple times, e.g., silage handling and smelling [55]. Motivation to devote time and interest to observing what is modelled will also influence learning, which may vary based on factors such as relevance, financial impact, complexity or prior experience of the information, process or practice.

Dairy A-C, as groups focussed on improving their grass-fed dairying systems of various sizes, utilised farm walks and formal discussion beforehand to prep the members about issues the host wanted feedback on as well as afterwards to debate different options for change. Key practices I saw explained at most meetings of these groups were calf rearing, involving questions around type of shed (concrete walls versus wood, hay bales stacked to create a den within an open barn, open-faced with tarps to pull down against rain and wind), location (separate sheds from the cow barns to avoid disease transmission, small or large pens for different groups), feeding (milk powder quantity, equipment) and weaning (approximate weight/age when transfer outside, "cake" or supplemental feed provided). Levels of cake bought into these low-input systems and fed to heifers and cows were a constant concern, fluctuating based on visual assessment of body condition. Many expressed hesitations at reducing $\mathrm{kg}$ of cake fed per day per animal to low levels reported by others in case it would negatively impact milk production, fertility, etc. Artificial insemination (AI) was another incredibly important practice described by the host in terms of weeks spent, number of semen straws used, percentage of sexed semen used, conception rates, etc. Participants' attention appeared quite high as the practices explained were common amongst their farms, so they were meaningfully engaging with what was being modelled and relating it to their previous experience using similar or different techniques (retention). Their motivation to dedicate time and interest to these modelled practices would have been positively influenced by the direct financial benefits posed, whether cost savings, increased efficiency or long-term profitability through improved herd health and fertility, for instance. I heard other factors outweighing financial concerns, however, that influenced the farmers' attention and motivation to engage with modelled behaviours-animal welfare, work-life balance, labour capabilities, etc.

Beef/Sheep A and B meetings with expert presentations involved minimal behaviour modelling, especially between participants as most explanation flowed from the expert to the farmers (e.g., mental health, large-scale veg production and processing). One notable exception, however, was when Beef/Sheep B visited a wool processing facility where they saw a demonstration from an expert grader on how to assess their wool for discolouration (highest price per $\mathrm{kg}$ for white wool rather than yellow, grey or black) and stains, clumping and dirtiness (e.g., straw, dung) (31 October 2018). The farmers had the motivation to dedicate time and effort to learning how the grading process worked because wool as a by-product must not be disposed of on-farm without a license; therefore, most producers sell what they annually shear to the British Wool Board. As the expert explained, if they must sell it, they should try to receive the best possible price rather than disregarding wool maintenance as worthless since the price per $\mathrm{kg}$ difference by grade could add up. Thus, financial incentive as an outcome expectation if the wool was maintained to a higher grade seemed to heighten attention, whereas at the outset I heard some dismissive comments and jokes about just burning it as opposed to paying the haulage fee and receiving so little in return. Additionally, the expert showed wool bundles of each grade, had the participants feel and look closely at each and then practice whether they could identify the probable grade for when they were assessing their own flock. That opportunity for enactive learning was particularly useful for retention and production rather than simply hearing the explanation and trying to apply it on-farm in future. 
Dairy D, as a new group, was interesting to observe as to how the participants engaged with each other and the experts/facilitator. Their first meeting involved an expert presentation by a veterinarian around the subject of calf health (28 November 2018). In speaking about the vital need to administer colostrum within two hours of calving, the participants started debating what the best method was. Five of the participants who had been actively farming for a number of years and were owner/operators in their dairy businesses were quite confident sharing their thoughts, past experience and practice techniques. Five participants were relief milkers and/or calf rearers who had come along with their employer; one who had been working on the same farm for a few years engaged in the discussion more by nodding and agreeing with comments, whilst the others sat quietly and did not demonstrate any familiarity with the topic. After about five minutes of discussion, the facilitator pulled up a plastic tube with a bag at the top and a ring about $2 / 3$ of the way up on the tube. "Can anyone tell me what this if for?" A few of the experienced farmers answered simultaneously that it represented the depth to which the tube needs to be inserted to make sure the colostrum is properly reaching the calf's leaky ruminant stomach. Based on plenty of expressions of "oh really?" and "ah okay" around the room, it sounded as though that was new vicarious learning around a previously implemented practice for many and there was meaningful perception of the modelled action (attention). They did not have the opportunity to put the learning into practice right then and instead would have to wait until the next calving season. By relating it to their previous knowledge (retention), however, certain participants should be able to perform that learnt technique when necessary, drawing upon the large amount of prior experience they have in administering colostrum (production). Due to the extreme consequence of piercing the calf's stomach if the tube is inserted too far though, those unfamiliar with the practice may not be confident in translating the knowledge gained into practice straight away, having only learned vicariously through explanation rather than an actual demonstration on a calf. Given the importance of administering colostrum correctly for calf health and future fertility, the overall motivation appeared quite high to learn the modelled technique.

The Veg Growers always incorporated behaviour modelling into their meetings. Having started with eight people sharing books, videos and experience about how to improve crop establishment, pest management, soil fertility, etc., the group had expanded hugely over the course of a few years. Thus, the group had developed the farm walk and potlock structure for their meetings to accommodate a larger group and learn from each other's operations. At their monthly meetings, I heard different approaches to intercropping explained, supplier recommendations offered, and community-supported agriculture (CSA) subscriptions compared for cost, delivery or pick-up locations, duration (e.g., all-year round or seasonal, which also influenced whether items were bought in to fill the hungry gap in early spring before crops were ready to harvest), number of items included, etc. I saw farmers demonstrate equipment used for spacing seeds along beds, irrigation, plowing, harvesting and weed control, which incited many shared examples of alternate techniques, processes and equipment from other participants. There was an interesting instance of behaviour modelling around salad washing (2 April 2019). As premium prices are sought for leaves that are undamaged and visually appealing for primary plating by chefs, the washing process needs to be extremely careful whilst also time efficient. The host farmer led us to that station on the farm and explained their process of triple rinsing, but the problem was the leaves were being transferred too many times between different crates. Others chimed in about their use of mesh netting to submerge the leaves, slanted tables to lay out the leaves and hose them down, and spinning slatted buckets. Then a grower interjected, "I repurposed wooden box frames and tacked wire mesh into the bottom. So when I rinse the leaves, the dirt and everything settles to the bottom or falls out. You just give it a good shake side to side to sift it out, rinse and repeat." The host responded enthusiastically as did a few others, asking more about the materials and any drawbacks (attention). They all had prior experience to draw on (retention) to assist with production, but the motivation to vicariously learn from her modelled practice was the simplicity of keeping the leaves in one container, thereby reducing labour time and potential damage from transfer leading to financial disbenefits. 


\subsection{Role Modelling}

Role modelling was also identified throughout the FDGs' interactions, though in comparison to the plethora of examples of behaviour modelling available from the farm walks (which specifically aim to promote demonstration and explanation by peer hosts), there were fewer examples from each group. The results will be presented by the factors under this element. Logically, there is overlap between the social learning elements as to factors that impact learning. Motivation to learn from peers' modelled actions is also a key component of this element, influenced by outcome expectations (what one anticipates will be the outcome of actions) based on one's own experiences as well as the perceived positive or negative feedback received by a role model [42]. If one had or knows of a terrible experience with a practice but the role model reaped significant rewards from it, for instance, one may have high motivation to learn how s/he did it differently or low motivation due to resistance informed by the poor former result. Estimation of the model's competence and prestige from outcome successes and failures, e.g., more or less successful, more or less clever, different context, etc., may also influence the perceived functional value and attention given to his/her modelled actions [42]. This may then influence self-efficacy, or one's beliefs about his/her capabilities to learn or perform actions at designated levels [47], in relation to the person modelling the action. Social norms and shared values, relevant to self-reflexivity as well, may also influence learning from peer modelling as people may have low motivation or perceive low functional value in and therefore pay little attention to information purveyed by someone seen to have drastically divergent values, e.g., low cleanliness or animal welfare standards [56].

Motivation to learn from peers based on the perceived positive or negative reinforcement incurred from modelled actions, decisions or processes was demonstrated in various cases. Dairy B visited one of the member's farms who had won a prestigious award from a large milk buyer the year before, which the participants brought up a few times in the discussion around whether he should change things he had asked about on the farm walk (25 April 2019). The group reinforced that he "must be doing something right" to receive that positive feedback, in addition to continued profitability, farm expansion, excellent grass growth, high fertility rates and good cow condition, suggesting he was a role model other members looked to for examples. During a meeting on irrigation, the Veg Growers also clearly referred to a member considered to be a particularly proficient role model on that topic (2 April 2019). The host explained his system of rolling out tubing along each bed for drip irrigation, for which he and other trainees working on the farm provided negative feedback-it took two people to complete, the tubes always got tangled and it was too time-consuming. In contrast, the host praised the role model member's system as much better-the tubes were affixed to a wooden bar and could be easily unrolled along the length of the beds. Growers who had worked on her farm as trainees positively reinforced the perception that it was simple and efficient, enhancing the members' motivation to learn that modelled action.

A negative feedback example, however, was observed at a Dairy $\mathrm{C}$ meeting. The meeting was hosted at a young new member's operation where he runs a flying herd (buying in heifers) rather than rearing his own replacement heifers as done in closed herds (7 November 2018). There were quite a few farmers with closed herds at the meeting who had been in the business for over 30 years, and their concerned response to his replacement strategy centred around disease risk, i.e., introducing bovine tuberculosis (bTB) into the herd. Partly, this demonstrated adherence to the social norm of disease risk avoidance, but the participants cited many examples of external peers who had received extremely negative feedback in the form of financial disbenefits from the resultant "shutdown" of their herds. Upon testing positive for bTB, the Government "shuts the herd down" or imposes restrictions on the movement of cattle between herds to try to control the spread of the disease. Shutdown also imposes extensive testing requirements, which means significant time, money and opportunity costs to the operation. When they challenged the host to reconsider his approach due to those outcome expectations and he dismissed their concerns with a shrug and "it's all luck anyway" and "I'm making money this way", they looked incredulous. A few older farmers came up to me during lunch and commented 
about how radical his approach was, and that "sometimes these groups are good to show you what you don't want to do [laughter]" (Conversation with farmer, Dairy C, 7 November 2018). This perceived negative reinforcement of the role model's practice suggested nobody would be changing their thinking to follow his example. Following up with the facilitator months later though, he commented that some members may have reacted viscerally in the moment (particularly amongst peers abiding by the same norms), but they may have ruminated on it and changed their thinking after considering the numbers and how much less it cost the host to buy in replacements than rear them (Conversation with Facilitator, Dairy C). Thus, the motivation to capitalise on the incentive of increased profitability from that approach may ultimately outweigh the shared value of risk minimisation and possibility of incurring negative outcomes.

Regarding estimation of the model's competence and prestige, Dairy B visited a farm in the Midlands for their away trip who was considered to be an industry leader in staff recruitment and employee management (17 September 2019). The farmer's ability to successfully recruit individuals from outside the industry through attractive advertisements, strong training programmes and career progression was praised as well as extensively inquired about by the members. Some expressed their frustrations and pitfalls with recruitment and staff management, suggesting they saw the host as more competent at that process and practice than they were. Similarly, Beef/Sheep A toured a beef finishing unit, which was larger and more profitable than any of their operations (25 October 2019). The participants praised the host's efficiency in feed utilisation over a short period of time and finishing weight as impressive and joked about whether he would be interested in buying any of their cattle to finish. A farmer from Dairy $\mathrm{C}$ referenced one of the people who he would consider to be a role model within the group. "[Farmer X] is someone that I really wish would speak more because ... you don't know for sure, but he seems to be very successful, he's expanding, he's doing things a little bit different ... but he's a very quiet chap, so he's someone I would love to tap into a bit more. I guess it's people who are doing a really good job and just don't like putting their hand up and speaking out loud." (Interview, Dairy C, 5 February 2019). He suggested that the facilitator has a big part to play in "developing him as a person within the group" and being aware in drawing out people who have valuable contributions to make. Thus, many people within and external to the FDGs were regarded as role models with competence and prestige, positively influencing members' motivation to learn from their modelled actions, thinking and processes.

Self-efficacy's impact on the FDG participants' learning was identified through their discussions about implementing a different course of action or thinking about things differently as modelled and their perceived capabilities to do so. The Veg Growers, for instance, had a meeting about community engagement at a farm with a thriving volunteer programme (5 March 2019). Many of the growers were asking how they were able to attract so many people to come and dedicate free labour. The lead grower highlighted the farm's social media engagement as being a key factor in their successful recruitment and maintenance of volunteer support. Most of the approximately 15 participants sitting around the table were under 35 years of age and about half looked mystified and the other half nodded emphatically. The discussion which ensued revealed the participants' divergent technological skills. One grower in her 20s commented that Twitter was a great way to announce volunteer days and Instagram kept people engaged if one posted frequent updates of what was being done or growing on the farm with aesthetically pleasing pictures. Another grower in her 20s commented that she did not understand either of those platforms and barely understood how to use a computer. Thus, her self-efficacy was very low and others in the group openly admitted resistance to wanting to learn about technology because they felt so ill-equipped and incapable of using it. This negatively impacted their motivation to learn from the host's process for volunteer engagement.

In interviews with the farmers, many commented that one of things they valued about their FDG participation was gaining confidence through interacting with their peers. "If they can do it, so can I" was a repeated statement, demonstrating self-efficacy in reference to the role models' competence and outcomes. One interview with a farming couple from Somerset in Dairy A specifically highlighted how interactions with FDG peers may improve self-efficacy. The male partner spoke very passionately 
about the need to surround yourself with role models in terms of being of a mind-set that strives for growth and is willing to take on risks. He and his partner were in the process of expanding their business, had taken on a large amount of debt for the first time, and he commented, "I respect certain peers who I interact with, many within our discussion group... I really respect their opinion, and they respect you asking sometimes. So I was talking to another farmer [in the group] last night, you know, on quite a confidential level about interest rates—and you interact and surround yourself by those people which give you confidence to do that [risk-taking] ... and the problem is, a lot of farmers don't do that." (Interview, Dairy A, 12 March 2019) (emphasis added). This demonstrates strong estimation of his role models' competence and high motivation to seek assistance from them on higher-level cognitive processes surrounding his business decision making. It also transitions nicely into the self-reflexivity results as he attributes development of his awareness and assessment of the way he thinks about his thinking (attitude and approach toward risk), or metacognitive development, to interaction with his peers.

\subsection{Self-Reflexivity}

If overt factors for the role modelling element were evidenced less than behaviour modelling, those demonstrating self-reflexivity were potentially even less frequent and explicit. The process of critically questioning one's ideas, beliefs, attitudes, assumptions, processes and practices in relation to what has been modelled may happen purely internally and therefore not have been vocalised at the meeting, it may not have been instantaneous but rather a delayed realisation after much consideration, or it may have been a gradual shift not specifically attributable to any one piece of information. Thus, simply because participants did not speak reflexively about their thinking in light of the modelled behaviours did not necessarily mean self-reflexivity was not occurring. Nevertheless, challenging interactions around the reasons why peers do or do not act or think in certain ways did elicit critical questioning by participants as to beliefs, assumptions and attitudes influencing their cognitive processing, outcome expectations and self-efficacy and whether they may want to change. The FDGs studied all involved participants asking questions of the expert or host farmer to varying extents for clarification and more information around different practices, processes and thoughts. However, the depth of sharing and discussion between the participants about their individualised practices, processes and particularly beliefs, values, feelings and judgments varied between the groups.

Reed et al. [41] point to the difference between "information transmission" and "deliberation" as types of social interaction through which learning may occur. With regard to the latter, Rist et al. [57] (p. 23) emphasise that social learning is a process through which "different actors can deliberate and negotiate rules, norms and power relations", allowing for learning and change beyond just the individual to the wider group. Fry and Thieme highlight the importance of the discursive process through which shared meanings or "shared cognitions" are co-constructed by the participants, enabled by "trust, cooperation, empathy, intuition and inspiration" built up and employed throughout the learning interactions [58] (p. 186). In these spaces for "communicative action" [59], the "actors involved have to be willing and able to negotiate as equals in an open communicative process, where diversity and conflict are driving forces for development and social learning" [58] (p. 186, emphasis added). Similarly, Beers et al. [7] found that significant learning resulted from what they label antithetic interactions or those involving opposition and debate, thereby highlighting the importance of critical discourse in not only promoting but evidencing self-reflexivity. The groups' structures, norms, guidance and expectations for capacity and skill development to engage in critical discourse with their peers that challenges the reasons behind their thoughts, processes and practices were found to be instrumental in promoting self-reflexivity.

An example from Dairy A involved a discussion about staff management (12 December 2018). Amongst joking between the participants ("can I sack my old man?"), the host farmer made a derisive comment about the lack of good labour supply and that even if you are loyal to them, it might not be extended back. They may get bored after a few years and leave. The facilitator then asked an employee of the host who was sitting in the meeting, "What makes you loyal as an employee to your 
employer?" Her answer was progression: "I don't want to stay anywhere I'm not progressing". This sparked an interesting comment from another farmer then about progression maybe not being everyone's goal-one of his employees has milked cows for him for over 20 years and values the steadiness of routine and the achievement of always being on time. Another farmer agreed, "Not everyone can be a manager". The host then conceded, "I guess what's key is understanding what staff want". He related this to the personality-type exercise the group had done at a former meeting, which he had then carried out with his staff. In finding out that certain people need to engage in pleasantries (e.g., about their weekends, families, etc.) before diving into speaking about the day's work tasks, he had reflexively assessed his management style. His attitude towards just wanting to get on with the work and the assumption staff felt the same in fact did not match their need to feel valued. Thus, he decided to make a conscious effort to change his attitude and behaviour to accommodate the different personality types/communication needs of his staff by engaging every morning in short catchups.

Modelled self-reflexivity was also observed in a Veg Growers' meeting (11 September 2018). Group members were invited to bring their favourite hand tools to the host farm to demonstrate what worked well in different contexts, saved time, cost a reasonable amount and improved efficiency. The host led us to a shed on the farm walk that was close to the beds, explaining her recent revelation that she should strategically store all the tools frequently needed in there rather than the main shed on the farm. This had stemmed from critically questioning her daily routines and realising how much time she was wasting walking across the yard multiple times throughout the day to get tools. Based on that example, many participants then spoke reflexively in front of the group as well as to each other about how they plan their space and how much time they could save if they put their supplies in more strategic places. That reaction may seem like common sense, making less work for themselves; however, if viewed from the perspective of a self-aware process of scrutiny and continuously questioning not just how but why one is doing something, the growers' engagement with the modelled behaviour relates to reducing inefficiency within their operations and willingness to change their setup rather than keep things in the same place simply because "we've always done it that way". In other meetings, I also heard growers engaging in debates based on positive or negative experience, literature, online forums and videos to inform their conflicting perspectives, e.g., challenging each other's pairing decisions for intercropping, soil and pest management techniques, composting, etc.

Social norms and values conflicts led to self-reflexivity in some of the interactions I observed between Dairy B participants. For instance, the changing way in which retailers are requiring handling of bull calves by their dairy suppliers elicited differing positions about public perception (28 March 2019). One of the major milk buyers in the UK is banning farmers from eliminating bull calves on-farm; instead, they must either be raised for beef on-farm or sold off. A few members complained about "militant vegans" creating smear campaigns of dairy farmers as contributing to that new policy, which many viewed as general misunderstanding by the public as to the economic inefficiency of keeping something (i.e., feeding, vaccinating, etc.) for which there was such a low market return. Another member, however, argued that public sentiment is extremely important to their businesses and that a wider industry move in that direction was only a matter of time. They were challenged to reconsider their assumption that investing in bull calves was not worth it by examples of dairy-beef collaborations that offered at least three times the amount per calf than livestock markets and the promise of a guaranteed buyer.

Another Dairy B meeting involved a discussion about the host farmer possibly expanding the operation by renting neighbouring fields. Opportunities to double one's grazing platform rarely arise, so he was struggling with the presumption that one must jump at the chance; but that would mean a larger herd and more work (25 April 2019). He had recently had a health scare and it made him and his partner realise they needed to reassess where they were going with the business and how they were going to get there. Having received his comparable farm profit (CFP) report at the start of the meeting so everyone had an idea what the business' figures were, the facilitator initiated an exercise where the group questioned him about his future goals. He spoke about wanting to provide for his 
kids' education, continue to run a profitable dairy, but he also wanted to get the right staff in place so he could learn how to step away a bit and maybe take day trips with his partner. One of his peers argued passionately, "Why would you expand when you're wanting to work less? We all need to live each day as if it was our last ... you don't want any wishes that you had done more than work on your deathbed. No regrets". This appeared to resonate with the host in critically questioning whether his idea of expanding matched with his values around family and wellbeing; however, he offered the counterargument of loving what he does and the fear of retiring and then losing one's purpose. That exchange shows how critical discourse with a peer may lead to self-reflexivity about one's cognitive processing and highlight how one's different values may conflict in certain situations.

The critical discourse observed at a Dairy C meeting exemplified such conflict between the host's values informing his decisions and the need for reflexivity (23 January 2019). The group and I sat around the host's living room drinking tea and coffee as he talked us through his CFP report. It was quite lopsided with costs incurred and debt. The ten members present dug for information about his decisions that had contributed to those numbers. He admitted that he still used a mixer wagon even though he had a large grazing platform; being a group of low-input producers, his peers challenged that decision. Additionally, he revealed his guilty habit of buying equipment and livestock on impulse. A significant stress in the immediate future was that he had a hefty loan payment due to the bank in less than four months. The host admitted he had booked 100 cows to be sold at auction before the due date, but he was not sure about selling them. The group inquired about different reasons why he might hesitate; in fact, it was because they were the first crossbreeds he had ever bred himself and he was sentimentally attached to them even though they were underperforming compared to his subsequent crossbreeds. His peers immediately challenged the contradiction behind what he was proposing-potentially losing his farm and not being able to support his partner and four small children by choosing not to sell assets that could easily make the payment amount because he felt sad to see them go. They argued vehemently that he needed to reassess his reasoning and how it reflected (or not) his values and commitment to his family. The conclusion was that he needed to critically evaluate his outlook on the herd using KPIs and clear goals of what he wants (e.g., cow size, calving block, cross, productivity), weeding out those which do not meet clear criteria.

The Beef/Sheep A and B groups involved either an expert or a host farmer presenting to the participants about a relevant topic or their operation. At the expert-led meetings, I observed no interaction amongst the participants during the meeting; the interactions were instead in the form of questions to the expert for clarification or more information. It was only afterwards over the buffet dinner, lunch or at the bar I heard conversations between individuals or in small groups. The topics discussed related to the presentation for at least some of the time (e.g., electronic tax filings, mental health warning signs), but they also branched off into general farming issues, sharing how they were handling young stock, bTB testing, planting, manure spreading, etc. Following the electronic tax filing presentation, for instance, I overheard two producers lamenting how complicated the system appeared, demonstrating low self-efficacy, but further comments revealed their general aversion to technology. Thus, their attitude towards technology was being challenged by the regulatory change requiring online filing, which may have led to self-reflexivity as to whether technology should have a role to play in their operation or whether they could learn how to use it rather than resist. This was, however, not vocalised.

The farmer host-led meetings included interaction between the host and participants and between the participants about what was being modelled to a more limited extent. For instance, Beef/Sheep A toured a large vegetable producer and processor's operation, which the coordinator clarified was intended to demonstrate the massive scale a family farm had reached through modernisation and investment (21 February 2019). In response to a question about whether and how Brexit would impact his business, the host gave a very dismissive answer about people still needing to eat, so demand would not suffer, and no concern about changing trade conditions. None of the beef and sheep farmers pushed back, though they are potentially going to become subject to tariffs for large export markets, 
e.g., lamb to France. Rather, the follow-up comments suggested his modelling reinforced some group members' beliefs and attitudes about negative trade projections being scare mongering. There was no more discussion and the group moved on to a new topic. For the person who asked the question and others in the group who may have felt differently (that Brexit does pose negative implications) but did not comment, that interaction may have caused some self-reflexivity about their beliefs. It was, however, not vocalised. Or it may have lowered their estimation of the role model's competence based on his divergent attitude from their own. From either perspective though, self-reflexivity was not demonstrated based on the modelled behaviour.

This lack of discussion observed between the Beef/Sheep group members about conflicting thoughts, beliefs, processes and practices is certainly not meant to suggest it never happens. Additionally, contradicting a host external to the group may have been difficult as a guest on his farm and Brexit remains a very divisive topic, which by the time of that meeting had been argued over for over two and a half years. Nevertheless, the group's structure, norms, guidance and expectations were not focussed on promoting engagement in critical discourse around differing ways in which the participants act, think or feel. As this fosters critical questioning of oneself as well as others, those FDGs' interactions were found to be less likely to promote self-reflexivity.

Benchmarking groups, on the other hand, have an annual meeting where they actively go through each farm's key performance indicators (KPIs) and critically discuss all costs, savings, profits and losses, which decisions could have been made differently and gather ideas for change from each other's suggestions and experiences. In talking with a founding member of Dairy B, the process of developing critical discourse within the group and capacity building over time to engage in self-reflexivity was apparent. "It was strange to start with ... well, we were all new to [benchmarking], we didn't quite know what to expect ... uh, we'd never discussed financial details with other farmers or be [sic.] open. Farmers ... if they discuss financial things, uh, normally you don't believe a word of what they're saying [laughter], but with this group, as the group evolved and we grew to trust each other and we shared our figures, none of us are in competition with each other. But we're all selling a product to whoever ... and if we could help each other, when we go through the CFPs, and Joe Bloggs' has only got 0.2 of a penny for insurance and mine's 0.8 , we want to know why his is so much lower and why mine's so much higher. And there are a lot of figures like that that we had no idea ... you know, farming-you're quite insular. And you've no idea whether it's a good price or a bad price what you're paying, you just pay insurance, for example, when the renewal comes around. You never questioned it ... but we learnt to question all our costs. And as we sort of grew to trust each other, we shared more and more financial details, and farming techniques. Whenever you go to a farm, there's always something you pick up that they're doing differently. You might not do it exactly the same when you come back [home to the farm], but you can adapt it" (Interview, Dairy B, 1 July 2019).

Having observed the three FDGs' benchmarking meetings, they were strategically structured to promote farmers challenging each other to reflect on what they had done over the past year and to be self-reflexive about "why do I do what I do?" from the standpoint of underlying beliefs, values, attitudes and assumptions. As stated by the Dairy B group member interviewed above, critical discourse was a norm that had developed over time within the group, so members expected this type of interaction. For example, Dairy B entered into a debate about how and when to dry cows off towards the end of their lactation cycle and the facilitator inserted an example from New Zealand (31 January 2019). Some in the group argued adamantly in favour of the benefits to the herd of having a stark cut-off for a month, but others argued about the higher availability of extra feed during that period in NZ versus the UK and the risk a month without milk sales introduces to the business' profitability. "What if you have loan payments to make? How do you survive?" A well-seasoned farmer in the group responded, "Well, you should be used to flux. You should have some [money] squirreled away from periods when the milk price was high". This revealed important beliefs, values and assumptions underlying decision making, challenging others to critically assess their prudence, anticipation of change and forward-thinking risk management and planning. These types of interactions demonstrated FDG participants' critical skills 
to be able to challenge their own and others' tacit assumptions about potentially taken-for-granted behaviours and cognitions within their businesses.

Dairy D was not a benchmarking group, however, and had newly formed the year I followed their meetings. Thus, the participants did not have an extensive shared history of collaboration with each other or basis of trust for not just sharing information, but critically challenging each other's assumptions and attitudes underpinning their thoughts, processes and practices. At their second meeting, the facilitator led us through an exercise where we assessed our values, goals and short-/long-term strategies for accomplishing them (27 March 2019). That exercise structured the discussion specifically to elicit reflexive thinking from the participants about what they are aiming to do in their businesses as well as personal lives, critically question the reasons behind those goals and share with each other. There were some very revealing exchanges that stemmed from that exercise, including one where two younger generation daughters expressed their desire to have been asked whether they wanted to be part of the farm succession vision for the operation rather than it automatically going to their brothers. One older generation mother then expressed her self-reflexive questions about whether her and her partner's values (e.g., equality, family harmony, etc.) had adequately factored into the decisions around how their farm succession plan would be carried out. This demonstrates how discussion tools and techniques may be used to foster self-reflexivity within FDGs.

\section{Discussion}

Thus, two of the social learning elements were identified throughout each of the FDGs' interactions. All FDGs promoted behaviour modelling and role modelling, involving interaction between the individuals and their environment leading to cognitive processing and learning about different options and opportunities for change based on modelled thoughts, beliefs, attitudes and actions. Observation translated into learning from behaviour modelling was found to depend on the participants' motivation to pay attention and retain the information based on factors like relevance, complexity, perceived (dis)benefits (e.g., cost savings, increased efficiency or long-term profitability), social concerns, personal and staff wellbeing, animal welfare, etc. This reinforces many studies that have found that demonstration or behaviour modelling by peers is an effective way to promote learning, but different ways in which the learning context is setup, type of information and how it is purveyed have an impact on the learning process [21]. Farmers should be as involved as possible in directing the learning topics to increase ownership of the process and facilitators should draw out the knowledge in the room, bringing in external experts if expertise is needed, but the groups' participation norms should be developed to expect active exchange between peers about the shared information and modelled behaviours [15].

With regard to role modelling, examples of learners estimating the model's positive or negative reinforcement for performing the action showed that they were informed, again, by financial gains or losses, external recognition and goal attainment, good employee feedback, simplicity of practice, etc. Estimation of models' competence and prestige also impacted the observers' motivation to learn from him/her, self-efficacy regarding their comparative capabilities to effectively implement what was modelled and outcome expectations based on what the model's outcomes were. These estimations may be difficult to deduce whether and how they are happening unless learners vocalise or demonstrate something related to their cognitive processing. Thus, observations of how learners evidenced the role modelling element of social learning may only represent a small fraction of role model estimations happening internally. As found by Prager and Creaney [15] in the context of FDGs and monitor farms, relationship building and trust between the participants are crucial to effectuate sharing and learning. These underpinning relational factors were important to the interactions amongst the FDG participants in this study as well, but they may specifically be considered foundational in the group members' estimations of role models, e.g., longer-term relationships may provide a better overview of people's history of positive/negative feedback, trust that the person has good intentions in presenting certain practices, etc. 
The self-reflexivity element of social learning, however, was not observed within all the groups. The interactions amongst the group members in Dairy A-D and the Veg Growers were structured in different ways to foster self-reflexivity by the participants. The Veg Growers example of modelled reflexivity by the host appeared to be a straightforward way to encourage others to engage in similar self-reflexivity around a shared topic of interest. Additionally, tools and techniques such as the vision and goal-setting exercise facilitated at the Dairy D meeting, specifically aimed at fostering critical questioning of one's current practices and possible strategies for change, may help promote self-reflexivity amongst participants. Finally, developing the groups' capacity for critical discourse to the point where it becomes a norm and expectation in terms of how they engage with each other was demonstrated by Dairy A-C in challenging each other's assumptions, values conflicts, attitudes and beliefs behind shared thoughts, processes and practices. Structuring FDG meetings around an expert presentation with little or no purposeful engagement between participants built in seemed to be least effective at promoting interactions that would foster self-reflexivity, as seen in the Beef/Sheep A and B groups. Additionally, their farm walks involving questioning of the hosts for clarification and information, low amounts of sharing between participants as to different approaches they take towards common issues, and not challenging each other's assumptions, attitudes and beliefs were still valuable for learning through behaviour modelling, but they did not produce examples of self-reflexivity. Again, internal reflexivity may have been happening from what was modelled and observed, but it was not overtly discussed and/or brought out through critical discourse with their peers.

Overall, all elements of social learning were not found to be occurring in the FDGs, as evidence of self-reflexivity was absent from the Beef/Sheep groups. That element was found to be promoted by fostering critical discourse about each other's attitudes, assumptions, values, beliefs, processes and practices through the group's interactions. If social learning is an objective of collaborative farmer learning in certain situations, then FDGs and other P2P learning mechanisms should aim to build the foundations of trust, structure, capacity and skills to effectively engage participants in critical discourse [58]. From extensive hours of observation, it appears that the process would best be facilitated by a trained, critically self-reflexive facilitator who actively supports the participants' development, monitors progress and challenges his/her assumptions about how to effectively support the group's evolving interactions [9]. Whether there is sufficient training and continuing professional development within the facilitation realm to provide this support in the UK agricultural sector is questionable and should be made a priority in the changing policy environment as a holistic, integrated approach towards strengthening farmers' knowledge and learning processes.

\section{Conclusions}

Social learning is a theory that has been applied in multiple different contexts to denote processes where actors learn from each other's knowledge, experience, perspectives, processes and practices. Applying the theory as originally conceptualised by Bandura and developed over the years from an educational learning theory perspective, the emphasis is on the cognitive learning process that occurs through interaction with one's environment. From that conceptual standpoint, this study was framed to investigate the interactions between participants within a sample of FDGs in South West England. The elements of behaviour modelling, role modelling and self-reflexivity guided the ethnographic design and implementation of the study, resulting in numerous examples of the elements playing out within the groups.

The evidence points to the conclusion that social learning, as understood from an adult cognitive learning theory standpoint, was occurring within five of the FDGs observed. Based on how the groups were structured and engaged (or not) in critical discourse, there was variance in the promotion of self-reflexivity by the various groups. Therefore, critical discourse may be understood as a factor influencing whether social learning is most effectively promoted. That finding underscores the important role of facilitation within the context of the groups in fostering critical discourse, e.g., developing capacity, skills, trust and understanding of that communication approach. Drawing on 
studies that highlight the need for skilled facilitation to effectively promote learning and innovation within networks, systems transitions, and adult learning interventions, there is a need for further research as to how facilitators may effectively develop and hone the skills for fostering critical discourse aimed at promoting self-reflexivity. Within the UK agricultural field, this speaks to the need for more research around and development of facilitators' learning opportunities, e.g., training, mentorship, continuing professional development, etc.

Additionally, more research is needed on critical discourse. How can farmers better develop their understanding, skills, confidence, trust and motivation to engage in critical discourse as a form of learning from and with their peers? Does the capacity to engage critically simply evolve over time through mutual engagement with familiar colleagues about shared challenges and opportunities? Do certain interventions speed up that capacity building process? What role does peer modelling of that skill play and how might that be fostered? Which methods or tools exist and may be utilised to encourage critical discourse for not just reflection on tasks and decisions but reflexivity as to values, attitudes, beliefs and assumptions informing one's perspective and practice, thereby contributing to metacognitive development?

FDGs are a mechanism through which social learning may be promoted within UK agricultural extension. Both individual and collective group change may be promoted through participants' learning processes involving interaction with, influence from and impact on their environment. As demonstrated within the FDGs in this study, social learning will depend on the interactions amongst the group members and may be effectively promoted through critical discourse around issues of shared concern and divergent thoughts, experiences and perspectives. Adult cognitive learning theories have been applied to many situations in which farmer learning is an objective, incorporating methods to encourage knowledge acquisition, information processing, reflection and reflexivity on values and assumptions, practice change, amongst other forms of learning. This article provides more understanding as to how FDGs and P2P interactions may be enhanced by fostering social learning through behaviour modelling, role modelling and self-reflexivity.

Funding: This research was funded in part by the Rowan Johnstone Studentship at the University of Exeter.

Acknowledgments: This research would not have been possible without the support and guidance of my doctoral supervisors, Matt Lobley and Michael Winter OBE (Professors at the University of Exeter, Centre for Rural Policy Research). I extend my sincere gratitude to Vanessa Rowan Johnstone for financially supporting this research Ph.D. I would like to thank Jonathan Doney (Lecturer at the University of Exeter, Graduate School of Education) for his incredibly helpful discussions and suggestions about educational learning theories. I would also like to thank Lisa van Dijk (Knowledge Exchange Programme Manager at the Royal Agricultural University) for her insights around farmer-led innovation, collaborative learning and facilitation. Finally, many thanks to the anonymous peer reviewers for their time spent providing comments and suggestions that improved the quality of this article.

Conflicts of Interest: The author declares no conflict of interest. The funder had no role in the design of the study; in the collection, analyses, or interpretation of data; in the writing of the manuscript, or in the decision to publish the results.

\section{References}

1. Baker, S.; Swales, D. Brexit Scenarios: An impact assessment. Horizons. Agriculture \& Horticulture Development Board. 2017. Available online: https://ahdb.org.uk/brexit/documents/Horizon_BrexitScenarios_ Web_2017-10-16.pdf (accessed on 29 April 2020).

2. Mitchell, I. The Implications of Brexit for UK, EU and Global Agricultural Reform in the Next Decade; Chatham House: London, UK, 2017. Available online: https://www.chathamhouse.org/sites/files/chathamhouse/ publications/research/2017-11-02-Mitchell2_0.pdf (accessed on 29 April 2020).

3. Dolinska, A.; D'Aquino, P. Farmers as agents in innovation systems. Empowering farmers for innovation through communities of practice. Agric. Syst. 2016, 142, 122-130. [CrossRef]

4. Kilelu, C.W.; Klerkx, L.; Leeuwis, C. Unravelling the role of innovation platforms in supporting co-evolution of innovation: Contributions and tensions in a smallholder dairy development programme. Agric. Syst. 2014, 118, 65-77. [CrossRef] 
5. Darnhofer, I.; Lamine, C.; Strauss, A.; Navarrete, M. The resilience of family farms: Towards a relational approach. J. Rural Stud. 2016, 44, 111-122. [CrossRef]

6. Klerkx, L.; van Mierlo, B.; Leeuwis, C. Evolution of systems approaches to agricultural innovation: Concepts, analysis and interventions. In Farming Systems Research into the 21st Century: The New Dynamic; Darnhofer, I., Gibbon, D., Dedieu, B., Eds.; Springer Dordrecht: Heidelberg, Germany, 2012; pp. 457-484.

7. Beers, P.J.; van Mierlo, B.; Hoes, A.-C. Toward an Integrative Perspective on Social Learning in System Innovation Initiatives. Ecol. Soc. 2016, 21, 33. [CrossRef]

8. Sewell, A.M.; Hartnett, M.K.; Gray, D.I.; Blair, H.T.; Kemp, P.D.; Kenyon, P.R.; Morris, S.T.; Wood, B.A. Using educational theory and research to refine agricultural extension: Affordances and barriers for farmers' learning and practice change. J. Agric. Educ. Ext. 2017, 23, 313-333. [CrossRef]

9. Leeuwis, C.; Aarts, N. Rethinking Communication in Innovation Processes: Creating Space for Change in Complex Systems. J. Agric. Educ. Ext. 2011, 17, 21-36. [CrossRef]

10. Spielman, D.J.; Birner, R. How Innovative is Your Agriculture? Using Innovation Indicators and Benchmarks to Strengthen National Agricultural Innovation Systems; World Bank: Washington, DC, USA, 2008. Available online: http://siteresources.worldbank.org/INTARD/Resources/InnovationIndicatorsWeb.pdf (accessed on 29 April 2020).

11. Rivera, W.M. Public Sector Agricultural Extension System Reform and the Challenges Ahead. J. Agric. Educ. Ext. 2011, 17, 165-180. [CrossRef]

12. Benson, A.; Jafry, T. The State of Agricultural Extension: An Overview and New Caveats for the Future. J. Agric. Educ. Ext. 2013, 19, 381-393. [CrossRef]

13. Ingram, J. Technical and Social Dimensions of Farmer Learning: An Analysis of the Emergence of Reduced Tillage Systems in England. J. Sustain. Agric. 2010, 34, 183-201. [CrossRef]

14. O'Kane, M.P.; Paine, M.S.; King, B.J. Context, Participation and Discourse: The Role of the Communities of Practice Concept in Understanding Farmer Decision-Making. J. Agric. Educ. Ext. 2008, 14, 187-201. [CrossRef]

15. Prager, K.; Creaney, R. Achieving on-farm practice change through facilitated group learning: Evaluating the effectiveness of monitor farms and discussion groups. J. Rural Stud. 2017, 56, 1-11. [CrossRef]

16. Šūmane, S.; Knickel, K.; Strauss, A.; Kunda, I.; de los Rios, I.; Rivera, M.; Chebach, T.; Ashkenazy, A.; Tisenkopfs, T. Local and farmers' knowledge matters! How integrating informal and formal knowledge enhances sustainable and resilient agriculture. J. Rural Stud. 2018, 59, 232-241. [CrossRef]

17. Prager, K.; Thomson, K. AKIS and Advisory Services in the United Kingdom. Report for the AKIS inventory (WP3) of the PRO AKIS Project. 2014. Available online: http://proakis.webarchive.hutton.ac.uk/sites/proakis. hutton.ac.uk/files/Final\%20Draft-\%20Country\%20Report\%20UK(1).pdf (accessed on 29 April 2020).

18. Kilpatrick, S. Education and training: Impacts on farm management practice. J. Agric. Educ. Ext. 2000, 7, 105-116. [CrossRef]

19. Hennessy, T.; Heanue, K. Quanitfying the Effect of Discussion Group Membership on Technology Adoption and Farm Profit on Dairy Farms. J. Agric. Educ. Ext. 2012, 18, 41-54. [CrossRef]

20. Hansen, B.G. Financial extension that challenges farmers' thinking in discussion clubs helps farmers improve their problem solving abilities. Agric. Syst. 2015, 132, 85-92. [CrossRef]

21. Ingram, J.; Chiswell, H.; Mills, J.; Debruyne, L.; Cooreman, H.; Koutsouris, A.; Pappa, E.; Marchand, F. Enabling learning in demonstration farms: A literature review. Int. J. Agric. Ext. 2018, 29-42.

22. Millar, J.; Curtis, A. Challenging the boundaries of local and scientific knowledge in Australia: Opportunities for social learning in managing temperate upland pastures. Agric. Hum. Values 1999, 16, 389-399. [CrossRef]

23. Campbell, J.T.; Koontz, T.M.; Bonnell, J.E. Does collaboration promote grass-roots behavior change? Farmer adoption of best management practices in two watersheds. Soc. Nat. Resour. 2011, 24, 1127-1141. [CrossRef]

24. Morgan, S.L. Social Learning among Organic Farmers and the Application of the Communities of Practice Framework. J. Agric. Educ. Ext. 2011, 17, 99-112. [CrossRef]

25. Illeris, K. A comprehensive understanding of human learning. In Contemporary Theories of Learning: Learning Theorists ... In Their Own Words; Illeris, K., Ed.; Routledge: Oxon, UK, 2018; pp. 1-14.

26. Kolb, D.A. Experiential Learning: Experience as the Source of Learning and Development; Prentice-Hall: Englewood Cliffs, NJ, USA, 1984. 
27. Mezirow, J. Transformative Learning Theory. In Transformative Learning in Practice: Insights from Community, Workplace, and Higher Education; Mezirow, J., Taylor, E.W., Associates, Eds.; Jossey-Bass: San Francisco, CA, USA, 2009; pp. 18-31.

28. Percy, R. The contribution of transformative learning theory to the practice of participatory research and extension: Theoretical reflections. Agric. Hum. Values 2005, 22, 127-136. [CrossRef]

29. Merriam, S.B. Adult learning theory: Evolution and future directions. In Contemporary Theories of Learning: Learning Theorists ... In Their Own Words; Illeris, K., Ed.; Routledge: Oxon, UK, 2018; pp. 83-96.

30. Wenger, E. A social theory of learning. In Contemporary Theories of Learning: Learning Theorists ... in Their Own Words; Illeris, K., Ed.; Routledge: Oxon, UK, 2018; pp. 219-228.

31. Wildemeersch, D.; Stroobants, V. Transitional learning and reflexive facilitation: The case of learning for work. In Contemporary Theories of Learning: Learning Theorists ... in Their Own Words; Illeris, K., Ed.; Routledge: Oxon, UK, 2018; pp. 229-242.

32. Bandura, A. Social Learning Theory; Prentice-Hall: Englewood Cliffs, NJ, USA, 1977.

33. Rodela, R. Social Learning, Natural Resource Management, and Participatory Activities: A reflection on construct development and testing. NJAS Wagening. J. Life Sci. 2014, 69, 15-22.

34. Bandura, A. Social Foundations of thought and Action: A Social Cognitive Theory; Prentice Hall: Englewood Cliffs, NJ, USA, 1986.

35. Jenkins, L.; Hall, H.; Raeside, R. Applications and Applicability of Social Cognitive Theory in Information Science Research; Edinburgh Napier University: Edinburgh, UK, 2018. Available online: https://www.napier.ac.uk/ \{\}/media/worktribe/output-1017697/applications-and-applicability-of-socialcognitive-theory-in-information-science-research-2.pdf (accessed on 29 April 2020).

36. Pahl-Wostl, C. The importance of social learning in restoring the multifunctionality of rivers and floodplains. Ecol. Soc. 2006, 11, 10. Available online: http://www.ecologyandsociety.org/vol11/iss1/art10/ (accessed on 29 April 2020). [CrossRef]

37. Rodela, R. Social Learning and Natural Resource Management: The Emergence of Three Research Perspectives. Ecol. Soc. 2011, 16, 30. [CrossRef]

38. Blackmore, C. (Ed.) Social Learning Systems and Communities of Practice; Springer: London, UK, 2010.

39. Wenger, E. Communities of Practice: Learning, Meaning, and Identity; Cambridge University Press: Cambridge, UK, 1998.

40. Argyris, C.; Schön, D. Organizational Learning II; Addison-Wesley: Reading, MA, USA, 1996.

41. Reed, M.S.; Evely, A.C.; Cundill, G.; Fazey, I.; Glass, J.; Laing, A.; Newig, J.; Parrish, B.; Prell, C.; Raymond, C.; et al. What is Social Learning? Ecol. Soc. 2010, 15. Available online: https://www.jstor.org/stable/26268235 (accessed on 29 April 2020). [CrossRef]

42. Schunk, D.H. Learning Theories: An Educational Perspective, 6th ed.; Pearson: Boston, MA, USA, 2012.

43. Giovazolias, T.; Themeli, O. Social Learning Conceptualization for Substance Abuse: Implications for Therapeutic Interventions. Eur. J. Couns. Psychol. 2014, 3, 69-88. [CrossRef]

44. Schön, D. The Reflective Practitioner. How Professionals Think in Action; Temple Smith: London, UK, 1983.

45. Pillow, W. Confession, catharsis, or cure? Rethinking the uses of reflexivity as methodological power in qualitative research. Int. J. Qual. Stud. Educ. 2003, 16, 175-196. [CrossRef]

46. Zimmerman, B.J.; Schunk, D.H. (Eds.) Self-Regulated Learning and Academic Achievement: Theoretical Perspectives, 2nd ed.; Erlbaum: Mahwah, NJ, USA, 2001.

47. Bandura, A. Self-efficacy: The Exercise of Control; Freeman: New York, NY, USA, 1997.

48. Bandura, A. Social cognitive theory: An agentic perspective. Annu. Rev. Psychol. 2001, 52, 1-26. [CrossRef]

49. Rose, D.C.; Keating, C.; Morris, C. Understand How to Influence Farmers' Decision-Making Behaviour: A Social Science Literature Review; AHDB: Kenilworth, UK, 2018. Available online: https://projectblue.blob.core. windows.net/media/Default/Imported20Publication\%20Docs/FarmersDecisionMaking_2018_09_18.pdf (accessed on 29 April 2020).

50. Brewer, J.D. Ethnography; Open University Press: Buckingham, UK, 2000.

51. Doney, J.; Parker, S.G.; Freathy, R. Enriching the historiography of Religious Education: Insights from oral life history. Hist. Educ. 2017, 46, 436-458. [CrossRef]

52. Defra Statistics: Agricultural Facts-Commercial Holdings at June 2018 (Unless Stated) South West. Available online: https://assets.publishing.service.gov.uk/government/uploads/system/uploads/attachment_data/file/ 866816/regionalstatistics_southwest_20feb20.pdf (accessed on 20 August 2020). 
53. Bailey, A.P.; Garforth, C.J.; Angell, B.; Scott, T.; Beedell, J.; Beechener, S.; Rana, R.B. Helping Farmers Adjust to Policy Reforms Through Demonstration Farms: Lessons from a Project in England. J. Farm Manag. 2006, 12, 613-625.

54. Lobley, M.; Saratsi, E.; Winter, M.; Bullock, J. Training farmers in agri-environmental management: The case of Environmental Stewardship in lowland England. Int. J. Agric. Manag. 2013, 3, 12-20.

55. Carolan, M.S. Introducing the concept of tactile space: Creating lasting social and environmental commitments. Geoforum 2007, 38, 1264-1275. [CrossRef]

56. Mills, J.; Gaskell, P.; Ingram, J.; Dwyer, J.; Reed, M.; Short, C. Engaging farmers in environmental management through a better understanding of behaviour. Agric. Hum. Values 2017, 34, 283-299. [CrossRef]

57. Rist, S.; Chidambaranathan, M.; Escobar, C.; Wiesmann, U.; Zimmermann, A. Moving from sustainable management to sustainable governance of natural resources: The role of social learning processes in rural India, Bolivia and Mali. J. Rural Stud. 2007, 23, 23-37. [CrossRef]

58. Fry, P.; Thieme, S. A social learning video method: Identifying and sharing successful transformation knowledge for sustainable soil management in Switzerland. Soil Use Manag. 2019, 35, 185-194. [CrossRef]

59. Habermas, J. The Theory of Communicative Action; Originally Published 1981; McCarthy, T., Translator; Beacon Press: Boston, MA, USA, 1984.

(C) 2020 by the author. Licensee MDPI, Basel, Switzerland. This article is an open access article distributed under the terms and conditions of the Creative Commons Attribution (CC BY) license (http://creativecommons.org/licenses/by/4.0/). 